\title{
UMA PALAVRA INICIAL
}

A Delta traz a público um número temático, especial, organizado por Daniel do Nascimento e Silva (UFRJ) e Viviane Veras (Unicamp), com quinze trabalhos de pesquisadores de universidades nacionais e uma estrangeira, resultado do evento "Meio século de teoria dos atos de fala: Austin e seus leitores". O evento, acontecido no Instituto de Estudos da Linguagem da Unicamp, foi uma justa homenagem a Kanavillil Rajagopalan, ao se aposentar. Na Apresentação, os organizadores Daniel e Viviane contextualizam o evento-surpresa (novembro de 2012) como reconhecimento pelo trabalho de Rajan no universo acadêmico e complementam as informações sobre os participantes e suas pesquisas.

Todos os que acompanham nossas publicações têm conhecimento de que números temáticos da Revista Delta continuam a trazer um conjunto de trabalhos de áreas específicas ou homenagens a linguistas, como é o caso deste $3^{\circ}$. número de 2016. Lembramos que mesmo organizados por convidados ou pela editoria geral, os artigos passam por avaliação feita pelos pares, seguindo os mesmos critérios dos volumes regulares.

Com essa merecida homenagem a um dos mais respeitados linguistas brasileiros, (re)conhecido internacionalmente, um dos idealizadores da Delta juntamente com Mary Kato, Fernando Tarallo e Leila Barbara, encerramos mais um ciclo de editores. Novas mudanças na editoria acontecem. Kanavillil Rajagopalan e Leila Barbara, antes editores, passam a ser, respectivamente, membro do conselho superior e editora chefe e Tony Berber Sardinha é o novo editor.

Nesses 30 anos de publicação ininterrupta da Revista Delta, Mary Kato e Leila Barbara foram editoras responsáveis e em 1996, Leila assumiu a editoria juntamente com Rajan, trazendo novos membros para a comissão executiva, incluindo Maria Aparecida Caltabiano, que nos últimos 20 anos trabalhou diretamente com eles, com responsabilidades variadas: além da organização, em parceria com John R. Schmitz, de um número especial sobre tradução (Delta 19 esp, 2003), acompanhava o processo de avaliação e publicação dos trabalhos dos volumes da Revista.

Durante todo esse período, mudanças foram acontecendo, reflexo do avanço tecnológico e consequentemente do universo das publicações acadê- 
micas: a Delta passou a ser a primeira revista da área de Linguística a integrar a "biblioteca eletrônica" SciELO - Scientific Electronic Library Online, que disponibiliza seus números desde 1997. Recuperamos aqui as palavras de Barbara, Caltabiano e Ikeda (Delta 17 esp, 2001: 137) sobre o fato:

Em 1996, uma consulta levada a efeito pelo CNPq, que na área de Letras e Lingüística foi coordenada pelo prof. Marcuschi, apontou as melhores revistas brasileiras em cada área na opinião dos pesquisadores. De posse desses dados, a FAPESP, selecionou, em 1997, as 35 mais indicadas, que entraram no Projeto Scielo. A revista D.E.L.T.A. foi a única da área de Lingüística e Letras, e está disponível on line (www.scielo.br).

Os trabalhos apresentados no simpósio - A Revista Científica no próximo Século - da $52^{a}$ Reunião Anual da SBPC, realizada em Brasília em julho de 2000, do qual participaram Luiz Antonio Marcuschi, Vilson Leffa e Leila Barbara (posteriormente publicados na Delta 17 especial/2001) trouxeram para a discussão a novidade da época: o impresso sendo substituído pelo "eletrônico". Diz Leffa sobre O Texto em Suporte Eletrônico:

O objetivo deste trabalho é descrever uma experiência de produção de texto informatizado. Para isso, mostra-se o que foi a criação do CD-ROM TELA (Textos em Lingüística Aplicada), destacando-se, entre outros aspectos, as diferenças que existem entre o texto impresso em papel e o texto em suporte eletrônico, as vantagens e desvantagem de cada mídia, os recursos da mídia eletrônica e as implicações que todos esses aspectos trazem para a produção e recepção do texto informatizado (p.121).

Dentre as vantagens, além da facilidade de acesso, Leffa ressalta: "O $\mathrm{CD}$ reúne cerca de 45.000 páginas de textos o que equivale, em termos comparativos, a 225 volumes de 200 páginas impressas em papel" (Leffa, Delta 17esp. 2001: 122). Marcuschi, em Revistas Brasileiras em Letras e Linguística, faz um levantamento dos "periódicos científicos" da área e apresenta sua opinião:

Nossa área ainda não despertou para a publicação editorial eletrônica. E isto deverá acontecer em breve, pois não se admite hoje que uma área do conhecimento não tenha periódicos sistematicamente editados pela via eletrônica (Marcuschi, Delta 17esp, 2001:90).

Embora registre que a Delta estava na "WEB [...] como reduplicação do texto em papel", a proposta de Marcuschi vai além:

Isto não equivale a apenas lançar na internet os trabalhos na forma como estão no papel. Trata-se de uma forma muito diferente de publicação. Falo em revistas eletrônicas com características hipertextuais e não em revistas atualmente impressas replicadas eletronicamente. Pois isto não 
seria suficiente. Este assunto é importante para o futuro. Seguramente, as revistas eletrônicas (reduplicação das atuais revistas em papel) é desejável pela facilidade que se teria em consultá-las, mas isso é pouco já que a tecnologia de revistas eletrônicas está bem mais avançada do que isso.

A Delta deixou de ser impressa em 2012. No universo acadêmico, não chegamos à proposta integral de Marcuschi, os rumos parecem ter sido outros, entretanto, há hoje uma busca de padronização das publicações acadêmicas que envolvem qualidade, metodologia, divulgação nacional e internacional e acesso aberto. Há um conjunto de "critérios, políticas e procedimentos de avaliação de periódicos científicos adotados pelo programa SciELO para a admissão e permanência de títulos na Coleção SciELO Brasil” (http://www. scielo.br/avaliacao/avaliacao_pt.htm). A Delta é avaliada como A1, pelo Qualis-Periódicos, sistema de avaliação da CAPES, que classifica os periódicos a partir de determinados critérios. "Esses veículos são enquadrados em estratos indicativos da qualidade - A1, o mais elevado" (http://capes.gov.br/ avaliacao/instrumentos-de-apoio/classificacao-da-producao-intelectual).

Em 2010, as revistas do LAEL (Programa de Estudos Pós-Graduados em Linguística Aplicada e Estudos da Linguagem) - Delta, Intercâmbio e Bakhtiniana - e vários periódicos da nossa universidade foram inseridos ao Portal de Revistas Eletrônicas da PUC-SP, baseado no Sistema Eletrônico de Editoração de Revistas (SEER). "O Portal possui uma Política Editorial de divulgação com Acesso Aberto a todas as produções periódicas com abrangência nacional e internacional" (http://revistas.pucsp.br/).

Se o objetivo inicial do grupo de professores que idealizaram a Delta era "preencher uma lacuna: a área não possuía um periódico de âmbito nacional" (na época, 1985) e o "objetivo primeiro da Revista era ser uma publicação com representatividade nacional, servindo à comunidade de lingüistas do país, e não apenas uma revista da PUCSP" (Delta 17esp, 2001:137), acreditamos que a meta foi alcançada: em todos esses anos se manteve ininterrupta e continua a ser reconhecida pela comunidade de linguistas e linguistas aplicados do País ao lado de outras publicações nacionais.

Esperamos que os leitores apreciem esta edição e continuem a prestigiar a Delta enviando trabalhos e propondo números.

Leila Barbara

(Pontificia Universidade Católica de São Paulo - PUC-SP) lbarbara@uol.com.br

Maria Aparecida Caltabiano (Pontifícia Universidade Católica de São Paulo - PUC-SP) cidacalt@pucsp.br 